\title{
Treatment of right ventricular dysfunction and heart failure in pulmonary arterial hypertension
}

\author{
Chakradhari Inampudi ${ }^{1}$, Ryan J. Tedford ${ }^{2}$, Anna R. Hemnes ${ }^{3}$, Georg Hansmann ${ }^{4}$, Harm-Jan Bogaard ${ }^{5}$, \\ Martin Koestenberger ${ }^{6}$, Irene Marthe Lang $^{7}$, Evan L. Brittain ${ }^{8}$
}

${ }^{1}$ Division of Cardiology, Department of Medicine, Vanderbilt University Medical Center, Nashville, TN, USA; ${ }^{2}$ Division of Cardiology, Department of Medicine, Medical University of South Carolina, Charleston, SC, USA; ${ }^{3}$ Division of Allergy, Pulmonary, and Critical Care Medicine, Department of Medicine, Vanderbilt University Medical Center, Nashville, TN, USA; ${ }^{4}$ Department of Pediatric Cardiology and Critical Care, Hannover Medical School, Hannover, Germany; ${ }^{5}$ Department of Pulmonary Medicine, Amsterdam UMC, Vrije Universiteit Amsterdam, Amsterdam, The Netherlands; ${ }^{6}$ Division of Pediatric Cardiology, Department of Pediatrics, Medical University Graz, Graz, Austria; ${ }^{7}$ Division of Cardiology, Department of Medicine, Medical University of Vienna, Vienna; ${ }^{8}$ Division of Cardiology, Department of Medicine, Vanderbilt University Medical Center and Vanderbilt Translational and Clinical Cardiovascular Research Center, Nashville, TN, USA

Contributions: (I) Conception and design: C Inampudi, G Hansmann, EL Brittain; (II) Administrative support: C Inampudi, G Hansmann, EL Brittain; (III) Provision of study materials: C Inampudi, G Hansmann, EL Brittain; (IV) Collection and assembly of data: NA (V) Data analysis and interpretation: None; (VI) Manuscript writing: All authors; (VII) Final approval of manuscript: All authors.

Correspondence to: Evan L. Brittain, MD, MSc. 2525 West End, Suite 300 - A, Nashville, TN 37203, USA. Email: evan.brittain@vumc.org.

\begin{abstract}
Right heart dysfunction and failure is the principal determinant of adverse outcomes in patients with pulmonary arterial hypertension (PAH). In addition to right ventricular (RV) dysfunction, systemic congestion, increased afterload and impaired myocardial contractility play an important role in the pathophysiology of RV failure. The behavior of the RV in response to the hemodynamic overload is primarily modulated by the ventricular interaction and its coupling to the pulmonary circulation. The presentation can be acute with hemodynamic instability and shock or chronic producing symptoms of systemic venous congestion and low cardiac output. The prognostic factors associated with poor outcomes in hospitalized patients include systemic hypotension, hyponatremia, severe tricuspid insufficiency, inotropic support use and the presence of pericardial effusion. Effective therapeutic management strategies involve identification and effective treatment of the triggering factors, improving cardiopulmonary hemodynamics by optimization of volume to improve diastolic ventricular interactions, improving contractility by use of inotropes, and reducing afterload by use of drugs targeting pulmonary circulation. The medical therapies approved for PAH act primarily on the pulmonary vasculature with secondary effects on the right ventricle. Mechanical circulatory support as a bridge to transplantation has also gained traction in medically refractory cases. The current review was undertaken to summarize recent insights into the evaluation and treatment of RV dysfunction and failure attributable to $\mathrm{PAH}$.
\end{abstract}

Keywords: Right ventricular dysfunction; heart failure; pulmonary arterial hypertension (PAH)

Submitted Mar 12, 2020. Accepted for publication May 13, 2020.

doi: $10.21037 / \mathrm{cdt}-20-348$

View this article at: http://dx.doi.org/10.21037/cdt-20-348

\section{Introduction}

Pulmonary arterial hypertension $(\mathrm{PAH})$ is a progressively fatal disease with a median survival of 7 years (1). The prognosis of the patients is closely linked to the right ventricle (RV) function and the ability of the $R V$ to adapt to the progressive increase in afterload. The development of clinical symptoms is closely linked to the development of RV dysfunction. The development of clinical right heart failure is characterized by maladaptive RV remodeling and RV-pulmonary arterial uncoupling. 


\section{The anatomy and physiology of the cardiopulmonary unit}

\section{Myofiber architecture of the $R V$}

The RV is a thin-walled structure that is triangular from the side and crescentic in cross-section. Embryologically, the $\mathrm{RV}$ is derived from cardiac precursor cells in the anterior or second heart field (2). It is distinct from the left ventricle $(\mathrm{LV})$ in its anatomic, electrical, and cellular configurations. Anatomically, the RV is composed of 3 distinct portions. The Inlet, trabeculated apex and the infundibulum or conus (outlet region) (3). The muscle fibers of RV myocardium are composed of 2 layers. The superficial layer arranged circumferentially in a direction parallel to the atrioventricular groove (AV) groove and continuity with the LV. The deep fibers aligned longitudinally from base to apex. The RV and LV are closely inter-related through the septum, shared epicardial circumferential myocytes, and the pericardium which forms the basis for the ventricular interdependence $(4,5)$.

\section{Myocardial mechanics of the $R V$}

The RV has a distinctive, peristaltic like contraction pattern that starts from the inlet portion and ends at the infundibulum. The subepicardial layer of the inflow tract acts as an early pressure generator and deforms the RV circumferentially during isovolumic contraction. The subendocardial layers contribute to longitudinal shortening during the ejection phase and the interventricular septum accounts for a significant portion of the global RV function $(6,7)$.

The mechanisms of RV pump function include (I) shortening of the longitudinal axis with traction of the tricuspid annulus towards the apex; (II) radial movement of the RV free wall (referred to as a bellows effect); (III) bulging of the interventricular septum into the $\mathrm{RV}$ during LV contraction, and (IV) stretching of the free wall over the septum (causing shortening in the anteroposterior direction). Longitudinal contraction is thought to contribute up $75 \%$ of RV contractility under physiological conditions, with a lesser contribution from radial contraction (8). It is unknown if these relative contributions change in disease conditions.

\section{Defining right heart failure}

The International Right Heart Failure Foundation Scientific Working Group proposed the following definition for right heart failure: "a clinical syndrome due to an alteration of structure and/or function of the right heart circulatory system that leads to sub-optimal delivery of blood flow (bigh or low) to the pulmonary circulation and/ or elevated venous pressures at rest or with exercise" (9). Exercise limitation, fatigue, and fluid retention are the cardinal manifestations of right heart failure. Right heart failure can also be defined by World Health Organization functional class IV symptoms with clinical signs of venous congestion with fluid retention and signs of decreased cardiac output (10).

\section{Pathophysiology of right ventricular failure in PAH}

The pathophysiology of RV failure involves a complex interplay of neurohormonal activation, inflammation, apoptosis, insufficient coronary perfusion, oxidative stress and metabolic shifts with a variable degree of fibrosis and hypertrophy (Figure 1). In situations like human immunodeficiency virus (HIV) associated PAH, infection/ inflammation of the myocardium and the intramural vessels has been shown to adversely affect the RV function as assessed by cardiac magnetic resonance imaging (15). The symptomatology, functional prognosis, and survival of patients with PAH depend on the ability of the RV to adapt to a progressive increase in afterload. This adaptation, often referred to as ventriculo-arterial coupling, is a measure of energy transfer assessed from the ratio between end-systolic elastance Ees (contractility) and arterial elastance Ea (afterload). The normal ratio is between 1.5 and 2.0 (16-18). $\mathrm{RV}$ adaptation is thought to represent a continuum, with true uncoupling occurring below a ratio of $0.7-0.8$. The adaptive phase (homeometric adaptation) is characterized by an increase in contractility with preserved stroke volume, whereas maladaptation (heterometric adaptation) is characterized by a dilated ventricle and eventually decreased stroke volume. During the adaptive phase, functional status, exercise capacity, and resting cardiac output are relatively well preserved. During the maladaptive phase, ventriculoarterial uncoupling results in inadequate energy transfer from the myocardium to the pulmonary circulation and subsequent right heart failure (19-22).

Studies of isolated myocytes (obtained from human RV septal biopsies and autopsy samples) revealed disparate contractile function between subtypes of PAH. Myocytes from idiopathic PAH has shown increase contractility relative to controls, even in end-stage disease, whereas systemic sclerosis related-PAH show impaired contractile 


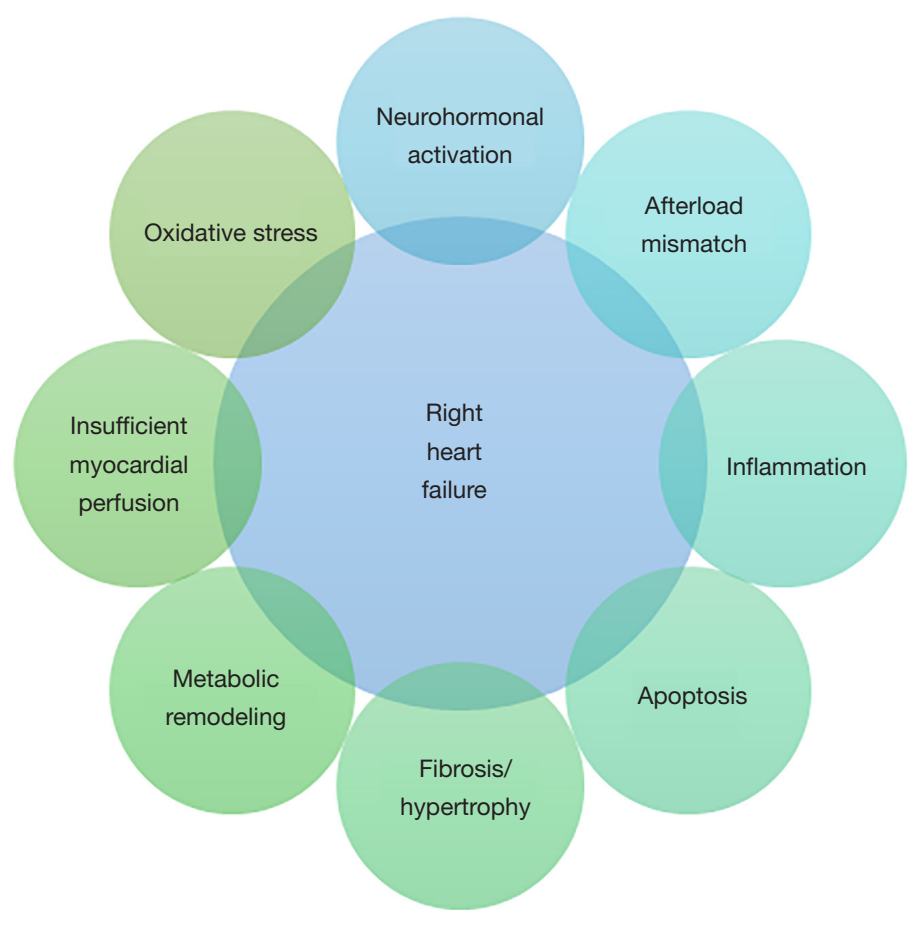

Figure 1 The Pathophysiology of Right Heart Failure (11-14).

function (11,23). Reduced RV contractile function has also been seen in animal models of ischemic LV dysfunction (12). Similar to the difference in contractile response, the $\mathrm{RV}$ adaptation to PAH has been evaluated in humans. Badagliacca et al. evaluated the morphologic adaptation of the RV in 60 patients with idiopathic PAH using echocardiography and cardiac magnetic resonance imaging. The study noted that concentric hypertrophy defined by $\mathrm{RV}$ mass/volume ratio $>0.46$ is a more favorable adaptation to increased afterload than the eccentric hypertrophy (mass/ volume <0.46) (13). The authors also noted in patients with narrow QRS, RV dyssynchrony is associated with the eccentric hypertrophy pattern suggesting that the mechanical delay could be another factor that influences the RV pump function in $\mathrm{PAH}$ patients $(14,24)$.

\section{$R V$ diastolic dysfunction:}

Numerous recent studies have detailed the presence of RV diastolic dysfunction in the setting of PAH $(25,26)$. The change in RV diastolic dysfunction may precede changes in the contractility in response to pressure overload as previously noted $(27,28)$. The curvilinear diastolic pressurevolume relationship can be determined through multibeat pressure-volume loops and is the optimal method to describe diastolic function. Echocardiography or cardiac magnetic resonance imaging measuring RV relaxation velocities have been proposed as a way to measure RV diastolic function, but these are load-dependent and prone to error measurement. Using a single-beat surrogate to compare 21 IPAH (20 women with an average age 45 years) and 7 controls, Rain et al. found significantly increased RV diastolic stiffness $(\beta)$ in patients with IPAH and increased passive tension at a single myocyte level. The study also noted that the RV diastolic stiffness was significantly and inversely correlated with lower stroke volume $[\beta-2.92$ (95\% CI for $\beta-4.34$ to $-1.50, \mathrm{P}=0.001$ )], 6-minute walk distance $[\beta-11.8(95 \% \mathrm{CI}$ for $\beta-20.0$ to $-3.9, \mathrm{P}=0.009)$ ] and closely correlated to RA pressure $[\beta 1.01$ (95\% CI for $\beta 0.52$ to $1.51, \mathrm{P}=0.001$ )], than the systolic properties (20). In a retrospective study by Trip et al., RV diastolic stiffness was linked to clinical progression in treatment naïve patients and to those on treatment (29). Despite marked differences in resting and reserve systolic function (30), RV diastolic stiffness appears similarly impaired in IPAH and systemic sclerosis related PAH (19). These elegant studies have paved the way to increasing understanding of the role of RV diastolic dysfunction in the pathophysiology of PAH. However, its role in clinical practice is yet to be well defined at this time due to its lack of reproducibility 
and accessibility. It is important to note that although the diastolic properties are impaired as noted above, the RV findings predominantly reflect end stage systolic dysfunction (dilated RV with elevated RVEDP) and the increase in the right atrial pressure is mainly due to the tricuspid regurgitation and RV systolic dysfunction.

\section{Left ventricular diastolic dysfunction and postcapillary pulmonary hypertension}

In patients with left ventricular diastolic dysfunction, postcapillary pulmonary hypertension occurs in response to a passive increase in pulmonary pressures that results from loss of left atrial and ventricular compliance $(31,32)$. Co-morbidities like atrial fibrillation, older age, obesity, and uncontrolled hypertension also contribute to the development of the PH $(33,34)$. A pre-capillary component may also develop, which is associated with worse outcomes and more severe hemodynamic perturbations (35). This increase in RV afterload leads to the activation of neurohormonal and molecular pathways (36). Initially, RV diastolic impairments are evident with preserved or enhanced contractility (37). This adaptive response is associated with right ventricular hypertrophy in approximately $45 \%$ of patients with post-capillary $\mathrm{PH}$ (38). In the progressive stage, the RV contractility is already at maximum and with progressive increases in afterload, RVPA uncoupling occurs (39-41). Human myocyte studies are yet to be performed to determine the contribution of contractile impairments. Additionally, in the setting of diastolic ventricular interaction and pericardial constraint, right ventricular dilation may even begin to compromise $\mathrm{LV}$ filling. At this phase, heart rate increases to maintain cardiac output. The increased heart rate leads to increased wall stress and oxygen demand. Long-standing high metabolic demand leads to right heart failure as the $\mathrm{RV}$ is unable to maintain cardiac output. In heart failure with preserved ejection fraction, the contractile impairment and the afterload mismatch will eventually lead to the development of RVD and failure (42-44). In a study of 1,454 patients with heart failure ( $\mathrm{n}=399$ enrolled by retrospective chart review and 219 by prospective enrollment) by Gerges $e t a l$. the overall prevalence of combined pre and post-capillary pulmonary hypertension $(\mathrm{CPcPH})$ was noted to be $12 \%$ in the HF cohort. The study noted that the measures of the RV-PA coupling were lower when compared to isolated post capillary $\mathrm{PH}$ and idiopathic $\mathrm{PAH}$. Additionally, $\mathrm{CpcPH}$ was associated with reduced median survival (54 vs. 102 months) when compared to patients with post capillary $\mathrm{PH}$ alone (45).

\section{Ventricular-ventricular interactions and LV impairment}

The ventricles share myocardial fibers and the interventricular septum. Approximately $30-60 \%$ of RV systolic performance can be attributed to $\mathrm{LV}$ contraction $(3,46)$. This systolic interaction is explained by the mechanical entrainment effect and as well as the LV contribution to coronary blood flow (and its role in maintaining systemic blood pressure) (25). With severe RV dilation and dysfunction, diastolic ventricular interdependence is exaggerated, which reduces the effective LV distending pressure (true LV preload), LV contractility and cardiac output. Given the above-mentioned dependence on LV contractility, RV contractility may therefore also decline. Evidence of chronic LV underfilling and perhaps the development of associated LV atrophy comes from observations after lung transplantation where the $\mathrm{LV}$ cannot accommodate a normal preload $(47,48)$.

More details on non-invasive imaging of RV dysfunction has been discussed elsewhere in this special issue (49).

\section{Coronary malperfusion/ischemia in advanced PAH}

Under normal conditions, the right coronary artery is perfused during systole and diastole, in contrast to the $\mathrm{LV}$ which receives most of its perfusion during diastole. As the $\mathrm{RV}$ remodels in response to chronically elevated afterload, the elevation in RV wall tension and transmural pressure reduces perfusion pressure such that blood flow occurs predominantly during diastole. Malperfusion of the right coronary artery then leads to RV ischemia and an increased risk of arrhythmias and can rapidly precipitate right ventricular failure (50-52).

\section{Diagnostic testing and principles of ICU monitoring}

The initial evaluation of suspected RV failure should include basic laboratories (e.g., electrolytes, blood counts, renal function), chest X-ray, electrocardiogram, and transthoracic echocardiography. Invasive hemodynamic monitoring allows continuous monitoring of cardiac output, central venous oxygen saturation (a marker of peripheral perfusion), and estimation of fluid status by 
measurement of filling pressures. Rapid identification and timely management of warning signs of imminent death such as declining central venous oxygenation, the elevation of lactate or liver enzymes, and a decline in urine output are critical. Supplemental oxygen should be provided to all patients with hypoxemia to maintain oxygen saturation $>90 \%$. In hypercapnic patients, non-invasive ventilation can be considered weighing the risks and benefits as positive pressure ventilation may further impair RV function $(53,54)$. Intubation should be avoided if possible due to the risk of cardiovascular collapse as described below. In situations where intubation is unavoidable, preservation of systemic blood pressure is key $(55,56)$.

\section{Goals of therapy}

(I) Treatment of triggering factors contributing to decompensation;

(II) Fluid management;

(III) Optimize cardiac function;

(IV) Initiation or escalation of targeted PAH therapy;

(V) Extracorporeal life support (ECLS);

(VI) Lung transplantation.

Recommendations specific to the diagnosis and treatment of RV dysfunction and failure in congenital heart disease (CHD) are outlined elsewhere in this special issue (57).

\section{Identification and management of triggering factors}

The initial evaluation of a patient with acute right ventricular failure requires the identification of a potentially reversible cause $(58,59)$. Known triggers precipitate decompensation (Table 1, Figure 2) in approximately $20-40 \%$ of patients. Infection, dysrhythmias, development of pulmonary embolus, unanticipated withdrawal of PAH specific therapy, and dietary indiscretion are some common triggers $(61,62)$.

\section{Infection}

Infection leading to clinical decompensation is frequently encountered in clinical practice (62). Infection is often poorly tolerated hemodynamically and a strong predictor of mortality (63). Common sources of infection include indwelling catheters and translocation of gut bacteria in conditions of low cardiac output with associated systemic venous congestion $(62,64)$.

\section{Atrial arrbythmias}

Atrial arrhythmias including atrial fibrillation and atrial flutter may precipitate RV failure. The altered structural and electrophysiological properties of the enlarged right atrium due to hypervolemia and chronic hypoxia altering the atrial substrate have been implicated as mechanisms for the development of atrial arrhythmias. Atrial fibrillation in the setting of RV dysfunction, when the heart rate is high, the reduction in the diastolic filling time influences the ventricular filling further raising right atrial pressure $(65,66)$. Beta-blockers and calcium channel blockers should be avoided due to negative inotropic effects (67). Medical management with antiarrhythmic drug therapy (e.g., amiodarone) or radiofrequency ablation has been used with varying success $(68,69)$. Rapid restoration of sinus rhythm with electrical cardioversion should be considered despite varying degrees of success in achieving and maintaining sinus rhythm $(68,70,71)$.

\section{Preload optimization}

Under normal physiologic conditions, the right atrial pressure is low from the high compliance of the RV. Systemic venous return is unimpeded and cardiac output is preserved. As RV remodeling progresses, sodium and water retention ensue, leading to systemic congestion. In cases of decompensation, patients often receive fluids due to hypotension at the time of presentation. Fluid administration often leads to an increase in right-sided filling pressure, shift of the interventricular septum to the left, and an increase in tricuspid regurgitation. The goals of management involve optimization of RV preload will reduce systemic congestion, tricuspid insufficiency, and deleterious ventricular interdependence. Effective preload reduction through diuresis will diminish ventricular interdependence and improve both $R V$ and $\mathrm{LV}$ function, including response to inotropic stimulation (Figure 2) (72).

Diuretics remain the mainstay of therapy to relieve congestion. The intensity of diuretic therapy needs varies based on coexistent renal disease. In some clinical situations where congestion leads to impaired drug absorption and visceral edema, large doses of loop diuretics or combination of loop diuretics and thiazides may be needed to augment diuresis via sequential nephron blockade. In some cases, congestion may be refractory of medical therapy and require ultrafiltration. Sodium restriction is a common clinical 
Table 1 Factors precipitating clinical decompensation

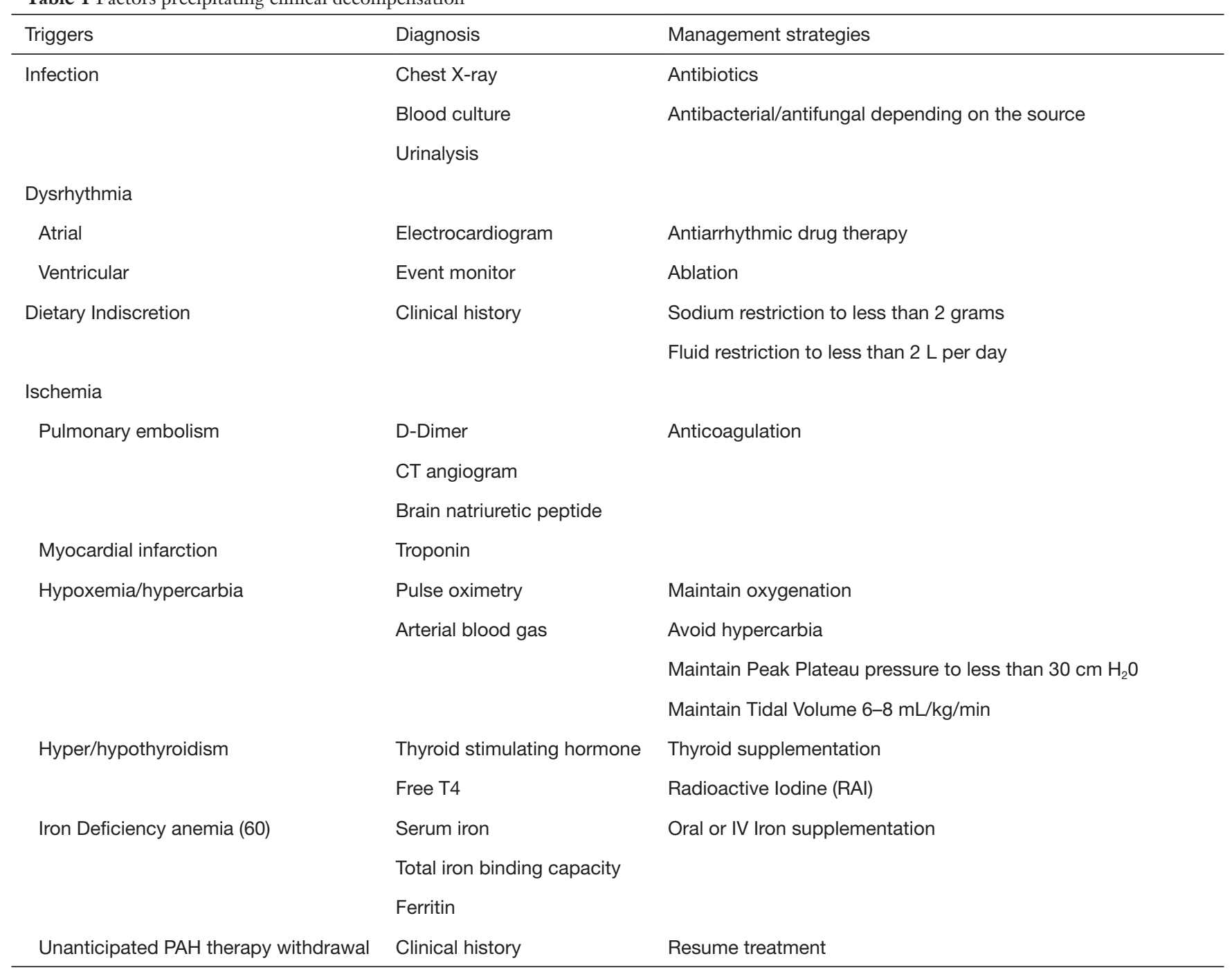

practice, although no large-scale studies have demonstrated benefit from this approach $(73,74)$.

\section{Afterload reduction}

An important mechanism to improve function in the pressure overloaded $\mathrm{RV}$ is to lower afterload. Reduction in $\mathrm{RV}$ afterload has been shown to improve cardiac function (75). The beneficial effect is through a multitude of mechanisms. (I) Reduction in RV wall tension; (II) reduced myocardial oxygen consumption (III) improved coronary macrovascular and microvascular perfusion (IV) increase in RV stroke volume 5. Improved LV filling through a reduction in $\mathrm{RV}$ septal shift. In patients presenting with decompensated RV failure with elevated right atrial pressure and depressed cardiac index, the use of intravenous prostacyclin analog is typically the first choice because of its rapid onset, titratability, magnitude of afterload reduction and reduction in mortality (76). In patients with newly diagnosed $\mathrm{PAH}$ and right heart failure, initiation of triple therapy with a prostacyclin analogue, endothelin receptor antagonist and phosphodiesterase inhibitor in combination has been shown to improve outcomes (77). In a retrospective study of 21 patients with severe idiopathic $\mathrm{PAH}$ who are treatment naïve upfront combination therapy with 3 agents is associated with decrease in right atrial pressure from $13 \pm 3$ to $5 \pm 2 \mathrm{mmHg}$, mean pulmonary artery pressure from $60 \pm 9$ to $42 \pm 5 \mathrm{mmHg}$ and pulmonary vascular resistance from 


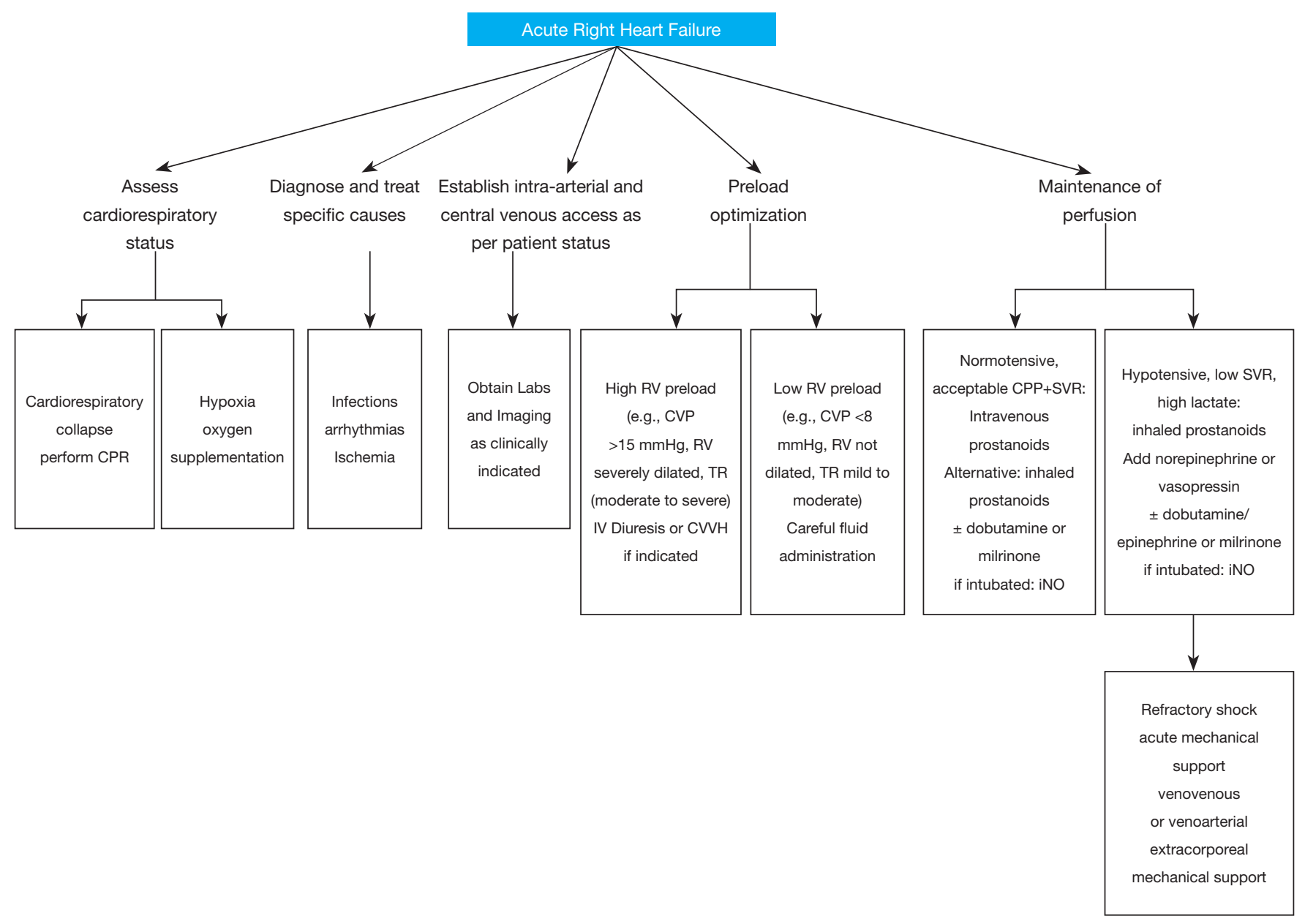

Figure 2 Algorithmic Management of acute right heart failure.

$16.4 \pm 4.4$ to $5.5 \pm 1.3$ Wood units (74). Prostacyclin analogs are generally administered by continuous intravenous infusion. However, such therapy places a considerable burden on the patients and is associated with side effects such as site pain and bloodstream infections. The emerging use of fully implantable pumps such as the gas driven LENUS Pro pump (implanted in the abdominal wall connected to the tunnel catheter and terminating in the right atrium) improves the subject comfort with a favorable safety profile $(78,79)$. Adjunctive use of corticosteroids and cyclophosphamide in addition to pulmonary vasodilators may improve outcomes in PAH secondary to systemic lupus erythematosus (80).

\section{Augment contractility}

In patients presenting with low output RV failure, inotropic therapy may be needed to improve cardiac output and restore ventriculo-arterial coupling without increasing RV afterload. Inotropes like dobutamine, milrinone, and levosimendan (Table 2) have been used in various preclinical and clinical studies (Figure 2) $(81,82)$. $\beta 1$ adrenergic agonist remains the inotropic agents of choice in most practices. Milrinone, a phosphodiesterase inhibitor and "inodilator" increases myocardial contractility, reduces systemic afterload, and reduces pulmonary vascular resistance (83). However, its use may be limited due to systemic vasodilation and resultant hypotension. Levosimendan was found to be more effective than dobutamine in animal models of right heart failure by optimizing hemodynamics and restoring RV-PA coupling (81,84-87). In a small placebo-controlled pilot study of 24 patients (Levosimendan $\mathrm{n}=15$; placebo, $\mathrm{n}=9$ ) that included patients with $\mathrm{PAH}$, the 
Table 2 Overview of inotropes and vasopressors

\begin{tabular}{lcccc}
\hline Drug & C.O & PVR & SVR & Heart Rate \\
\hline Dobutamine & $\uparrow \uparrow$ & $\downarrow$ & $\downarrow$ & $\uparrow$ \\
Milrinone & $\uparrow \uparrow$ & $\downarrow$ & $\downarrow$ & \\
Levosimendan & $\uparrow \uparrow$ & $\downarrow$ & $\downarrow$ & $\uparrow \uparrow$ \\
Dopamine & $\uparrow$ & $\uparrow$ & $\uparrow$ & $\uparrow \uparrow$ \\
Epinephrine & $\uparrow \uparrow$ & $\uparrow / \downarrow$ & $\uparrow \uparrow$ & $\uparrow$ \\
Norepinephrine & $\uparrow$ & $\uparrow$ & $\uparrow \uparrow$ & $\uparrow \uparrow$ \\
Vasopressin & $\uparrow / \downarrow$ & $\uparrow / \downarrow$ & & \\
\hline
\end{tabular}

use of Levosimendan was associated with a mean decrease of $12 \% \pm 9 \%$ in pulmonary vascular resistance and a change in mean pulmonary arterial pressure was a decrease of $14 \% \pm 4 \%$ at 24 hours when compared to placebo (88). Similar results were noted in a prospective single arm study performed in 9 patients with idiopathic $\mathrm{PAH}$ and associated right heart failure (89). Future larger studies are needed to determine the safety and efficacy in levosimendan in this patients with $\mathrm{PAH}$ who experience higher morbidity and mortality (90).

\section{Maintain right ventricular perfusion}

Many patients may present with low systemic vascular resistance or it may decrease during therapy. This is often accompanied by the development of multiorgan failure and $\mathrm{RV}$ ischemia. A primary goal of increasing systemic vascular resistance is to restore perfusion pressure. Restoration of perfusion pressure will increase $L V$ afterload, $L V$ contractility and thus RV contractility. This eventually facilitates diuresis. The use of vasopressors such as norepinephrine, phenylephrine, or vasopressin to increase systemic vascular resistance and thus augmenting aortic root pressure has been used with varying success as they reduce $\mathrm{RV}$ ischemia (Table 2, Figure 2) $(58,86,91)$. The use of norepinephrine has been shown to restore normal perfusion pressure and, in some cases, also improve right ventricular function and right ventricular-pulmonary arterial coupling $(92,93)$.

\section{Management of pericardial effusion in $\mathrm{PAH}$}

The development of pericardial effusion in a patient with $\mathrm{PAH}$ signifies poor prognosis. Its presence signifies an element of right heart failure as it is associated with higher right atrial pressure than those without the effusion.
Currently there are no guidelines, but available evidence suggests conservative management for those with small to moderate effusions and treatment of large effusions is controversial. The European executive summary in 2004 suggested that treatment of pericardial effusion in the setting of tamponade is recommended $(94,95)$.

\section{Ventilation strategies in PAH}

Pathophysiological insults such as apnea and hypoventilation, fluctuating blood pressure, increased sympathetic activity arising from fluid shifts, changes in preload, hypoxia, and hypercarbia exacerbate PVR, which can worsen RV failure $(96,97)$. Oxygen is a potent pulmonary vasodilator and high flow oxygen has been shown to increase cardiac index and reduce PVR in patients with pulmonary hypertension (98). Intubation and mechanical ventilation should be avoided when possible because they increase RV afterload and decrease right ventricular stroke volume which may precipitate a cardiovascular collapse $(96,97)$. When intubation is unavoidable, maintaining peak plateau pressures to less than 30 $\mathrm{cmH}_{2} \mathrm{O}$, tidal volume at $6-8 \mathrm{~mL} / \mathrm{kg} / \mathrm{min}$ and auto-PEEP are essential to minimize the adverse effects on RV afterload and contractile function (99).

\section{Pulmonary artery denervation}

The sympathetic nervous system and the activation of renin-angiotensin axis contribute to the development and progression of PAH (100-102). In the PADN-1 study, 21 patients with idiopathic $\mathrm{PAH}, 13$ patients received pulmonary artery denervation procedure and 8 served as controls. Pulmonary artery denervation has been shown to improve functional capacity in the form of significant improvement in 6 min walk distance $(324 \pm 21$ to $491 \pm 38 \mathrm{~m}$, 
$\mathrm{P}<0.006)$ and hemodynamics in patients not responding to medical therapy (103). It is important to note that data on the efficacy of pulmonary artery denervation are lacking in patients with acute RV failure. Existing evidence suggests the beneficial effects of pulmonary artery denervation in improving hemodynamics, cardiac function and in attenuating progressive remodeling of the pulmonary arteries and RV (104). The ongoing randomized multicentered sham-controlled study (Safety and Efficacy of Pulmonary Artery Denervation in Patients with Pulmonary Arterial Hypertension (PADN-CFDA) which aims to enroll 128 patients will provide more definitive safety and effectiveness data (NCT03282266).

\section{Atrial septostomy}

The first atrial septostomy as a treatment for PAH was performed by Rich and Lam in 1983 (105). The intervention involved creating a hole between the right and left atria thereby allowing shunting of blood from right to left and thus reducing wall stress. The shunting of blood leads to a decrease in arterial oxygen saturation and also increases in left ventricular preload and cardiac output. The procedure typically reserved for select patients with right ventricular failure and syncope $(106,107)$. In a recent systematic review and meta-analysis of 16 studies comprising 204 patients by Khan et al, atrial septostomy led to a statistically significant reduction in right atrial pressure and an increase in cardiac index. The pooled incidence of short ( $<30$ days) and long term ( $>30$ days) procedural related mortality was noted to be 14.6 and $37.7 \%$ (108). The procedure is limited by systemic arterial oxygen desaturation, the potential for paradoxical embolic events and procedure-related mortality.

\section{Mechanical support of the failing $R V$}

Despite maximal medical management, right heart failure can be irreversible. The use of mechanical circulatory support is gaining traction due to its ability to reduce right ventricular preload and afterload while providing pump function. These changes also lead to a reduction in tricuspid regurgitation and improvement in left ventricular filling due to less septal bowing. The exact timing of initiation of mechanical support is a matter of debate. In conditions of medically refractory cases of right heart failure, it is important to involve a multidisciplinary team including cardiologists, pulmonologists, cardiac surgery and intensivists to determine the need for mechanical support. The most important consideration during the evaluation should include patients bridging potential to a more durable therapy such as lung transplantation (109). Contraindications to mechanical circulatory support include the inability of the patient to be on anticoagulation, irreversible neurologic injury, and futile cases in which the patient is not eligible for transplant. The field of mechanical support witnessed major advances in the last decade. Improvement in a pump design with less thrombosis and heating issues, newer oxygenator designs that can be used for long periods with lower resistance, development of pumpless oxygenators, heparin-coated tubing circuits requiring less systemic heparinization have allowed for increased utilization of mechanical circulatory support $(110,111)$. Recently, the ARIA Pulmonary Balloon Pump with first-in-man experience (United States Patent 9039925) has been designated as Breakthrough Device by the FDA to reduce RV afterload by increasing pulmonary artery compliance.

\section{Extracorporeal Membrane Oxygenation (ECMO) and ECLS}

ECLS may be considered as a bridge to lung transplantation or as a bridge to recovery in treatment naïve or nonoptimized patients (Figure 2) (111). Modes of support include Venovenous Extracorporeal membrane oxygenation (VV-ECMO) or Venoarterial Extracorporeal membrane oxygenation (VA-ECMO). In cases where oxygenation is a limiting factor VV-ECMO is used. In patients with RV failure from $\mathrm{PAH}$ in whom pump function is compromised VA-ECMO is used for support. Alternative modes of support include Arteriovenous Nova lung and Pulmonary Artery-Left Atrium Novalung, Hechingen, Germany. These are pumpless devices with a low resistance diffusion membrane. They are primarily useful to remove carbon dioxide but are limited in their ability to provide oxygenation support due to restricted blood flow through the device from low cardiac output or small cannula sizes. In patients following lung transplantation, pulmonary vascular resistance improves rapidly and leads to an increase in cardiac output and left ventricular filling. In such a situation the LV may not handle the high normal cardiac output that occurs in the immediate post-operative period. In a study of 50 patients (23 vs. 17 vs. 13) with severe $\mathrm{PAH}$ who received bilateral lung transplant with post-operative ECMO use compared to patients who received heart-lung transplant and bilateral lung transplant and without post- 
operative ECMO support, the use of ECMO has been used to reduce the development of grade III primary graft dysfunction as noted by reduction in primary graft scores and improvement in 90 day survival (100\% vs. 82 vs. $85 \%)$ (110,112-114).

\section{Right ventricular assist devices (RVAD)}

RVAD serves to unload the RV leading to favorable supply-demand profile. The use of RVAD in patients with PAH is not considered an ideal treatment strategy as it does not address pressure overload which is the main pathophysiologic mechanism that leads to RV failure. At this time the use of RVAD in PAH is limited to case reports (115). Different types of RVAD exist at this time. They can be surgically or percutaneously implanted. They divert blood from Inferior vena cava or Right atrium to Pulmonary artery or left atrium bypassing the RV. The CentriMag pump (St. Jude, Minneapolis, Minnesota), or Impella RP catheter (Abiomed Inc, Danvers, MA) is such a type of device. Use of RVADs may also be limited by the risk of pulmonary edema in patients with concomitant $\mathrm{LV}$ diastolic dysfunction. This associated increase in pulmonary and capillary pressures may also predispose to pulmonary hemorrhage. The role of partial support devices and lower flow rates is physiologically intriguing but requires further study (116).

\section{Lung transplantation and heart-lung transplantation in PAH}

Bilateral lung transplantation remains the mainstay of therapy in cases of medically refractory right heart failure in PAH. Patients who are at high risk are recommended to be considered for lung transplantation. The European Respiratory Society pulmonary hypertension 2015 guidelines categorize patients as high risk if the mortality exceeds $10 \%$ on the current treatment over 1 year $(73,112,117-121)$. In an effort to decrease the death rate on the transplant waiting list, a lung allocation score has been implemented in the United States in May 2005 and subsequently revised in 2015 (122). The revised score allowed modifications to the existing variables and added relative weight to the variables used to predict the mortality risk (123). The allocation score ranges from 0 to 100 and it is calculated for each registered candidate age $>12$ years. The higher score corresponds to higher chances of receiving an organ. It is important to recognize that the LAS may not reflect the severity of PAH (124-126). Approximately $1.5 \%$ of patients receive lung transplants for IPAH between January 1995 to June 2018 (127). Patients who received lung transplants between 1990 and 2013 for PAH, the 3 -month mortality is reported to be $23 \%$. In the same era, the patients who survived to 1 year, the conditional median survival was noted to be 10 years (128).

\section{Conclusions}

The development of right heart failure is associated with poor clinical outcomes in patients with $\mathrm{PAH}$. Available therapies are largely supportive and do not directly target the right heart remodeling and failure. The use of extracorporeal membrane oxygenation as a bridge to transplantation has improved survival for selected patients. There remains a considerable need for studies that provide an improved understanding of the pathophysiological mechanisms involved in right heart remodeling.

\section{Acknowledgments}

Funding: None.

\section{Footnote}

Provenance and Peer Review: This article was commissioned by the Guest Editors (Martin Koestenberger, HarmJan Bogaard and Georg Hansmann) for the series "Right Ventricular Dysfunction" published in Cardiovascular Diagnosis and Therapy. The article was sent for external peer review organized by the Editor-in-Chief and the editorial office.

Peer Review File: Available at http://dx.doi.org/10.21037/ cdt-20-348

Conflicts of Interest: All authors have completed the ICMJE uniform disclosure form (available at http://dx.doi. org/10.21037/cdt-20-348). The series "Right Ventricular Dysfunction" was commissioned by the editorial office without any funding or sponsorship. GH, HJB and MK served as the unpaid Guest Editors of the series. Dr. RJT reports other from Actelion, other from Merck, other from Abiomed, personal fees and other from Medtronic, personal fees from United Therapeutics, personal fees from Arena Pharmaceuticals, personal fees from Aria Inc, outside the submitted work. IML reports grants and other from 
Actelion, grants and other from AOPOrphan Pharam, other from United Therapeutics, other from Ferrer, other from Astra Zeneca, outside the submitted work. HJB reports grants from Actelion, grants from Ferrer, outside the submitted work. GH reports grants from German Research Foundation, grants from The Federal Ministry of Education and Research, grants from European Pediatric Pulmonary Vascular Disease Network, outside the submitted work. ARH reports personal fees from actelion, personal fees from Bayer, personal fees from complexa, personal fees from PHPrecisionMed, personal fees from united therapeutics, outside the submitted work. The authors have no other conflicts of interest to declare.

Ethical Statement: The authors are accountable for all aspects of the work in ensuring that questions related to the accuracy or integrity of any part of the work are appropriately investigated and resolved.

Open Access Statement: This is an Open Access article distributed in accordance with the Creative Commons Attribution-NonCommercial-NoDerivs 4.0 International License (CC BY-NC-ND 4.0), which permits the noncommercial replication and distribution of the article with the strict proviso that no changes or edits are made and the original work is properly cited (including links to both the formal publication through the relevant DOI and the license). See: https://creativecommons.org/licenses/by-nc-nd/4.0/.

\section{References}

1. Benza RL, Miller DP, Barst RJ, et al. An evaluation of long-term survival from time of diagnosis in pulmonary arterial hypertension from the REVEAL Registry. Chest 2012;142:448-56.

2. Verzi MP, McCulley DJ, De Val S, et al. The right ventricle, outflow tract, and ventricular septum comprise a restricted expression domain within the secondary/anterior heart field. Dev Biol 2005;287:134-45.

3. Haddad F, Hunt SA, Rosenthal DN, et al. Right ventricular function in cardiovascular disease, part I: Anatomy, physiology, aging, and functional assessment of the right ventricle. Circulation 2008;117:1436-48.

4. Dell'Italia LJ. The right ventricle: anatomy, physiology, and clinical importance. Curr Probl Cardiol 1991;16:653-720.

5. Naeije R, Badagliacca R. The overloaded right heart and ventricular interdependence. Cardiovasc Res
2017;113:1474-85.

6. Buckberg GD, Group R. The ventricular septum: the lion of right ventricular function, and its impact on right ventricular restoration. Eur J Cardiothorac Surg 2006;29 Suppl 1:S272-8.

7. Brown SB, Raina A, Katz D, et al. Longitudinal shortening accounts for the majority of right ventricular contraction and improves after pulmonary vasodilator therapy in normal subjects and patients with pulmonary arterial hypertension. Chest 2011;140:27-33.

8. Kovács A, Lakatos B, Tokodi M, et al. Right ventricular mechanical pattern in health and disease: beyond longitudinal shortening. Heart Fail Rev 2019;24:511-20.

9. Mehra MR, Park MH, Landzberg MJ, et al. Right heart failure: toward a common language. Pulm Circ 2013;3:963-7.

10. Olsson KM, Halank M, Egenlauf B, et al. Decompensated right heart failure, intensive care and perioperative management in patients with pulmonary hypertension: Updated recommendations from the Cologne Consensus Conference 2018. Int J Cardiol 2018;272S:46-52.

11. Rain S, Handoko ML, Trip P, et al. Right ventricular diastolic impairment in patients with pulmonary arterial hypertension. Circulation 2013;128:2016-25.

12. van der Velden J, de Jong JW, Owen VJ, et al. Effect of protein kinase $\mathrm{A}$ on calcium sensitivity of force and its sarcomere length dependence in human cardiomyocytes. Cardiovasc Res 2000;46:487-95.

13. Badagliacca R, Poscia R, Pezzuto B, et al. Right ventricular remodeling in idiopathic pulmonary arterial hypertension: adaptive versus maladaptive morphology. J Heart Lung Transplant 2015;34:395-403.

14. Badagliacca R, Poscia R, Pezzuto B, et al. Right ventricular dyssynchrony in idiopathic pulmonary arterial hypertension: determinants and impact on pump function. J Heart Lung Transplant 2015;34:381-9

15. Frustaci A, Petrosillo N, Vizza D, et al. Myocardial and microvascular inflammation/infection in patients with HIV-associated pulmonary artery hypertension. AIDS 2014;28:2541-9.

16. Fourie PR, Coetzee AR, Bolliger CT. Pulmonary artery compliance: its role in right ventricular-arterial coupling. Cardiovasc Res 1992;26:839-44.

17. Tedford RJ, Mudd JO, Girgis RE, et al. Right ventricular dysfunction in systemic sclerosis-associated pulmonary arterial hypertension. Circ Heart Fail 2013;6:953-63.

18. Burkhoff D, Sagawa K. Ventricular efficiency predicted by an analytical model. Am J Physiol 1986;250:R1021-7. 
19. Konstam MA, Kiernan MS, Bernstein D, et al. Evaluation and Management of Right-Sided Heart Failure: A Scientific Statement From the American Heart Association. Circulation 2018;137:e578-e622.

20. Harjola VP, Mebazaa A, Celutkiene J, et al. Contemporary management of acute right ventricular failure: a statement from the Heart Failure Association and the Working Group on Pulmonary Circulation and Right Ventricular Function of the European Society of Cardiology. Eur J Heart Fail 2016;18:226-41.

21. Vieillard-Baron A, Naeije R, Haddad F, et al. Diagnostic workup, etiologies and management of acute right ventricle failure : A state-of-the-art paper. Intensive Care Med 2018;44:774-90.

22. Amsallem M, Mercier O, Kobayashi Y, et al. Forgotten No More: A Focused Update on the Right Ventricle in Cardiovascular Disease. JACC Heart Fail 2018;6:891-903.

23. Hsu S, Kokkonen-Simon KM, Kirk JA, et al. Right Ventricular Myofilament Functional Differences in Humans With Systemic Sclerosis-Associated Versus Idiopathic Pulmonary Arterial Hypertension. Circulation 2018;137:2360-70.

24. Badagliacca R, Reali M, Poscia R, et al. Right Intraventricular Dyssynchrony in Idiopathic, Heritable, and Anorexigen-Induced Pulmonary Arterial Hypertension: Clinical Impact and Reversibility. JACC Cardiovasc Imaging 2015;8:642-52.

25. Naeije R, Manes A. The right ventricle in pulmonary arterial hypertension. Eur Respir Rev 2014;23:476-87.

26. Rudski LG, Lai WW, Afilalo J, et al. Guidelines for the echocardiographic assessment of the right heart in adults: a report from the American Society of Echocardiography endorsed by the European Association of Echocardiography, a registered branch of the European Society of Cardiology, and the Canadian Society of Echocardiography. J Am Soc Echocardiogr 2010;23:685713; quiz 686-8.

27. Gaynor SL, Maniar HS, Bloch JB, et al. Right atrial and ventricular adaptation to chronic right ventricular pressure overload. Circulation 2005;112:I212-8.

28. Alaa M, Abdellatif M, Tavares-Silva M, et al. Right ventricular end-diastolic stiffness heralds right ventricular failure in monocrotaline-induced pulmonary hypertension. Am J Physiol Heart Circ Physiol 2016;311:H1004-13.

29. Trip P, Rain S, Handoko ML, et al. Clinical relevance of right ventricular diastolic stiffness in pulmonary hypertension. Eur Respir J 2015;45:1603-12.

30. Hsu S, Houston BA, Tampakakis E, et al. Right Ventricular
Functional Reserve in Pulmonary Arterial Hypertension. Circulation 2016;133:2413-22.

31. Vachiéry JL, Tedford RJ, Rosenkranz S, et al. Pulmonary hypertension due to left heart disease. Eur Respir J 2019;53:1801897.

32. Vachiéry JL, Adir Y, Barbera JA, et al. Pulmonary hypertension due to left heart diseases. J Am Coll Cardiol 2013;62:D100-8.

33. Rosenkranz S, Kramer T, Gerhardt F, et al. Pulmonary hypertension in HFpEF and HFrEF: Pathophysiology, diagnosis, treatment approaches. Herz 2019;44:483-90.

34. Hoeper MM, Barbera JA, Channick RN, et al. Diagnosis, assessment, and treatment of non-pulmonary arterial hypertension pulmonary hypertension. J Am Coll Cardiol 2009;54:S85-96.

35. Tampakakis E, Shah SJ, Borlaug BA, et al. Pulmonary Effective Arterial Elastance as a Measure of Right Ventricular Afterload and Its Prognostic Value in Pulmonary Hypertension Due to Left Heart Disease. Circ Heart Fail 2018;11:e004436.

36. Haddad F, Doyle R, Murphy DJ, et al. Right ventricular function in cardiovascular disease, part II: pathophysiology, clinical importance, and management of right ventricular failure. Circulation 2008;117:1717-31.

37. Rommel KP, von Roeder M, Oberueck C, et al. LoadIndependent Systolic and Diastolic Right Ventricular Function in Heart Failure With Preserved Ejection Fraction as Assessed by Resting and Handgrip Exercise Pressure-Volume Loops. Circ Heart Fail 2018;11:e004121.

38. Burke MA, Katz DH, Beussink L, et al. Prognostic importance of pathophysiologic markers in patients with heart failure and preserved ejection fraction. Circ Heart Fail 2014;7:288-99.

39. Melenovsky V, Hwang SJ, Lin G, et al. Right heart dysfunction in heart failure with preserved ejection fraction. Eur Heart J 2014;35:3452-62.

40. Gorter TM, Obokata M, Reddy YNV, et al. Exercise unmasks distinct pathophysiologic features in heart failure with preserved ejection fraction and pulmonary vascular disease. Eur Heart J 2018;39:2825-35.

41. Singh I, Rahaghi FN, Naeije R, et al. Right VentricularArterial Uncoupling During Exercise in Heart Failure With Preserved Ejection Fraction: Role of Pulmonary Vascular Dysfunction. Chest 2019;156:933-43.

42. Gorter TM, van Veldhuisen DJ, Bauersachs J, et al. Right heart dysfunction and failure in heart failure with preserved ejection fraction: mechanisms and management. Position statement on behalf of the Heart Failure 
Association of the European Society of Cardiology. Eur J Heart Fail 2018;20:16-37.

43. Guazzi M. Pulmonary hypertension in heart failure preserved ejection fraction: prevalence, pathophysiology, and clinical perspectives. Circ Heart Fail 2014;7:367-77.

44. Guazzi M, Gomberg-Maitland M, Arena R. Pulmonary hypertension in heart failure with preserved ejection fraction. J Heart Lung Transplant 2015;34:273-81.

45. Gerges M, Gerges C, Pistritto AM, et al. Pulmonary Hypertension in Heart Failure. Epidemiology, Right Ventricular Function, and Survival. Am J Respir Crit Care Med 2015;192:1234-46.

46. Damiano RJ Jr, La Follette P r, Cox JL, et al. Significant left ventricular contribution to right ventricular systolic function. Am J Physiol 1991;261:H1514-24.

47. Knight DS, Steeden JA, Moledina S, et al. Left ventricular diastolic dysfunction in pulmonary hypertension predicts functional capacity and clinical worsening: a tissue phase mapping study. J Cardiovasc Magn Reson 2015;17:116.

48. Avriel A, Klement AH, Johnson SR, et al. Impact of Left Ventricular Diastolic Dysfunction on Lung Transplantation Outcome in Patients With Pulmonary Arterial Hypertension. Am J Transplant 2017;17:2705-11.

49. Truong U, Haddad F, Koestenberger M, et al. State -of-the-Art Update on Non-Invasive Imaging of RV Dysfunction in Pulmonary Hypertension. Cardiovasc Diagn Ther 2020;10:1604-24.

50. van Wolferen SA, Marcus JT, Westerhof N, et al. Right coronary artery flow impairment in patients with pulmonary hypertension. Eur Heart J 2008;29:120-7.

51. Gómez A, Bialostozky D, Zajarias A, et al. Right ventricular ischemia in patients with primary pulmonary hypertension. J Am Coll Cardiol 2001;38:1137-42.

52. Gibbons Kroeker CA, Adeeb S, Shrive NG, et al. Compression induced by RV pressure overload decreases regional coronary blood flow in anesthetized dogs. Am J Physiol Heart Circ Physiol 2006;290:H2432-8.

53. Held $M$, Walthelm J, Baron S, et al. Functional impact of pulmonary hypertension due to hypoventilation and changes under noninvasive ventilation. Eur Respir J 2014;43:156-65.

54. Olsson KM, Frank A, Fuge J, et al. Acute hemodynamic effects of adaptive servoventilation in patients with precapillary and post-capillary pulmonary hypertension. Respir Res 2015;16:137.

55. Viitanen A, Salmenpera M, Heinonen J. Right ventricular response to hypercarbia after cardiac surgery. Anesthesiology 1990;73:393-400.
56. Viitanen A, Salmenpera M, Heinonen J, et al. Pulmonary vascular resistance before and after cardiopulmonary bypass. The effect of PaCO2. Chest 1989;95:773-8.

57. Santens B, Van De Bruaene A, De Meester P, et al. Diagnosis and treatment of right ventricular dysfunction in congenital heart disease. Cardiovasc Diagn Ther 2020;10:1625-45.

58. Hoeper MM, Granton J. Intensive care unit management of patients with severe pulmonary hypertension and right heart failure. Am J Respir Crit Care Med 2011;184:1114-24.

59. Lahm T, McCaslin CA, Wozniak TC, et al. Medical and surgical treatment of acute right ventricular failure. J Am Coll Cardiol 2010;56:1435-46.

60. Cao F, Sun D, Li C, et al. Long-term myocardial functional improvement after autologous bone marrow mononuclear cells transplantation in patients with STsegment elevation myocardial infarction: 4 years followup. Eur Heart J 2009;30:1986-94.

61. Haddad F, Peterson T, Fuh E, et al. Characteristics and outcome after hospitalization for acute right heart failure in patients with pulmonary arterial hypertension. Circ Heart Fail 2011;4:692-9.

62. Sztrymf B, Souza R, Bertoletti L, et al. Prognostic factors of acute heart failure in patients with pulmonary arterial hypertension. Eur Respir J 2010;35:1286-93.

63. Campo A, Mathai SC, Le Pavec J, et al. Outcomes of hospitalisation for right heart failure in pulmonary arterial hypertension. Eur Respir J 2011;38:359-67.

64. Niebauer J, Volk HD, Kemp M, et al. Endotoxin and immune activation in chronic heart failure: a prospective cohort study. Lancet 1999;353:1838-42.

65. Tongers J, Schwerdtfeger B, Klein G, et al. Incidence and clinical relevance of supraventricular tachyarrhythmias in pulmonary hypertension. Am Heart J 2007;153:127-32.

66. Ochi H, Izumi S, Murakami R, et al. Superior vena cava flow and tricuspid anular motion after cardioversion of atrial fibrillation, and role of right atrial relaxation on systolic venous return. Am J Cardiol 1991;68:1335-9.

67. Provencher S, Herve P, Jais X, et al. Deleterious effects of beta-blockers on exercise capacity and hemodynamics in patients with portopulmonary hypertension. Gastroenterology 2006;130:120-6.

68. Wanamaker B, Cascino T, McLaughlin V, et al. Atrial Arrhythmias in Pulmonary Hypertension: Pathogenesis, Prognosis and Management. Arrhythm Electrophysiol Rev 2018;7:43-8.

69. Cirulis MM, Ryan JJ, Archer SL. Pathophysiology, 
incidence, management, and consequences of cardiac arrhythmia in pulmonary arterial hypertension and chronic thromboembolic pulmonary hypertension. Pulm Circ 2019;9:2045894019834890.

70. Olsson KM, Nickel NP, Tongers J, et al. Atrial flutter and fibrillation in patients with pulmonary hypertension. Int J Cardiol 2013;167:2300-5.

71. Małaczyńska-Rajpold K, Komosa A, Blaszyk K, et al. The Management of Supraventricular Tachyarrhythmias in Patients with Pulmonary Arterial Hypertension. Heart Lung Circ 2016;25:442-50.

72. Szabó G, Soos P, Bahrle S, et al. Adaptation of the right ventricle to an increased afterload in the chronically volume overloaded heart. Ann Thorac Surg 2006;82:989-95.

73. Delcroix M, Naeije R. Optimising the management of pulmonary arterial hypertension patients: emergency treatments. Eur Respir Rev 2010;19:204-11.

74. Galiè N, Humbert M, Vachiery JL, et al. 2015 ESC/ERS Guidelines for the diagnosis and treatment of pulmonary hypertension: The Joint Task Force for the Diagnosis and Treatment of Pulmonary Hypertension of the European Society of Cardiology (ESC) and the European Respiratory Society (ERS): Endorsed by: Association for European Paediatric and Congenital Cardiology (AEPC), International Society for Heart and Lung Transplantation (ISHLT). Eur Heart J 2016;37:67-119.

75. D'Alto M, Badagliacca R, Argiento P, et al. Risk Reduction and Right Heart Reverse Remodeling by Upfront Triple Combination Therapy in Pulmonary Arterial Hypertension. Chest 2020;157:376-83.

76. Sitbon O, Vonk Noordegraaf A. Epoprostenol and pulmonary arterial hypertension: 20 years of clinical experience. Eur Respir Rev 2017;26:160055.

77. Sitbon O, Jais X, Savale L, et al. Upfront triple combination therapy in pulmonary arterial hypertension: a pilot study. Eur Respir J 2014;43:1691-7.

78. Kurzyna M, Malaczynska-Rajpold K, Koteja A, et al. An implantable pump Lenus pro(R) in the treatment of pulmonary arterial hypertension with intravenous treprostinil. BMC Pulm Med 2017;17:162.

79. Richter MJ, Harutyunova S, Bollmann T, et al. Longterm safety and outcome of intravenous treprostinil via an implanted pump in pulmonary hypertension. J Heart Lung Transplant 2018;37:1235-44.

80. Jais X, Launay D, Yaici A, et al. Immunosuppressive therapy in lupus- and mixed connective tissue diseaseassociated pulmonary arterial hypertension: a retrospective analysis of twenty-three cases. Arthritis Rheum 2008;58:521-31.

81. Kerbaul F, Rondelet B, Demester JP, et al. Effects of levosimendan versus dobutamine on pressure load-induced right ventricular failure. Crit Care Med 2006;34:2814-9.

82. Tavares-Silva M, Alaa M, Leite S, et al. Dose-Response Head-to-Head Comparison of Inodilators Dobutamine, Milrinone, and Levosimendan in Chronic Experimental Pulmonary Hypertension. J Cardiovasc Pharmacol Ther 2017;22:485-95.

83. Botha P, Parry G, Dark JH, et al. Acute hemodynamic effects of intravenous sildenafil citrate in congestive heart failure: comparison of phosphodiesterase type- 3 and -5 inhibition. J Heart Lung Transplant 2009;28:676-82.

84. Missant C, Rex S, Segers P, et al. Levosimendan improves right ventriculovascular coupling in a porcine model of right ventricular dysfunction. Crit Care Med 2007;35:707-15.

85. Kerbaul F, Rondelet B, Motte S, et al. Effects of norepinephrine and dobutamine on pressure load-induced right ventricular failure. Crit Care Med 2004;32:1035-40.

86. Price LC, Wort SJ, Finney SJ, et al. Pulmonary vascular and right ventricular dysfunction in adult critical care: current and emerging options for management: a systematic literature review. Crit Care 2010;14:R169.

87. Vildbrad MD, Andersen A, Holmboe S, et al. Acute effects of levosimendan in experimental models of right ventricular hypertrophy and failure. Pulm Circ 2014;4:511-9.

88. Kleber FX, Bollmann T, Borst MM, et al. Repetitive dosing of intravenous levosimendan improves pulmonary hemodynamics in patients with pulmonary hypertension: results of a pilot study. J Clin Pharmacol 2009;49:109-15.

89. Martyniuk TV, Arkhipova OA, Kobal EA, et al. [Possibilities of using levosimendan in patients with idiopathic pulmonary hypertension]. Ter Arkh 2012;84:83-8.

90. Hansen MS, Andersen A, Nielsen-Kudsk JE. Levosimendan in pulmonary hypertension and right heart failure. Pulm Circ 2018;8:2045894018790905.

91. Granton J, Moric J. Pulmonary vasodilators--treating the right ventricle. Anesthesiol Clin 2008;26:337-53, vii.

92. Ghignone M, Girling L, Prewitt RM. Volume expansion versus norepinephrine in treatment of a low cardiac output complicating an acute increase in right ventricular afterload in dogs. Anesthesiology 1984;60:132-5.

93. Hirsch LJ, Rooney MW, Wat SS, et al. Norepinephrine and phenylephrine effects on right ventricular function in experimental canine pulmonary embolism. Chest 1991;100:796-801. 
94. Keller R, Ragaz A, Borer P. Predictors for early mortality in patients with long-term oxygen home therapy. Respiration 1985;48:216-21.

95. Hemnes AR, Gaine SP, Wiener CM. Poor outcomes associated with drainage of pericardial effusions in patients with pulmonary arterial hypertension. South Med J 2008;101:490-4.

96. MacKnight B, Martinez EA, Simon BA. Anesthetic management of patients with pulmonary hypertension. Semin Cardiothorac Vasc Anesth 2008;12:91-6.

97. Blaise G, Langleben D, Hubert B. Pulmonary arterial hypertension: pathophysiology and anesthetic approach. Anesthesiology 2003;99:1415-32.

98. Roberts DH, Lepore JJ, Maroo A, et al. Oxygen therapy improves cardiac index and pulmonary vascular resistance in patients with pulmonary hypertension. Chest 2001;120:1547-55.

99. Jardin F, Vieillard-Baron A. Right ventricular function and positive pressure ventilation in clinical practice: from hemodynamic subsets to respirator settings. Intensive Care Med 2003;29:1426-34.

100. Velez-Roa S, Ciarka A, Najem B, et al. Increased sympathetic nerve activity in pulmonary artery hypertension. Circulation 2004;110:1308-12.

101. Ciarka A, Doan V, Velez-Roa S, et al. Prognostic significance of sympathetic nervous system activation in pulmonary arterial hypertension. Am J Respir Crit Care Med 2010;181:1269-75.

102. Morrell NW, Atochina EN, Morris KG, et al. Angiotensin converting enzyme expression is increased in small pulmonary arteries of rats with hypoxia-induced pulmonary hypertension. J Clin Invest 1995;96:1823-33.

103. Chen SL, Zhang FF, Xu J, et al. Pulmonary artery denervation to treat pulmonary arterial hypertension: the single-center, prospective, first-in-man PADN-1 study (first-in-man pulmonary artery denervation for treatment of pulmonary artery hypertension). J Am Coll Cardiol 2013;62:1092-100.

104.Zhang H, Chen SL. Pulmonary Artery Denervation: Update on Clinical Studies. Curr Cardiol Rep 2019;21:124.

105. Rich S, Lam W. Atrial septostomy as palliative therapy for refractory primary pulmonary hypertension. Am J Cardiol 1983;51:1560-1.

106. Doyle RL, McCrory D, Channick RN, et al. Surgical treatments/interventions for pulmonary arterial hypertension: ACCP evidence-based clinical practice guidelines. Chest 2004;126:63S-71S.
107. Sandoval J, Rothman A, Pulido T. Atrial septostomy for pulmonary hypertension. Clin Chest Med 2001;22:547-60.

108. Khan MS, Memon MM, Amin E, et al. Use of Balloon Atrial Septostomy in Patients With Advanced Pulmonary Arterial Hypertension: A Systematic Review and MetaAnalysis. Chest 2019;156:53-63.

109. Rajagopal K, Hoeper MM. State of the Art: Bridging to lung transplantation using artificial organ support technologies. J Heart Lung Transplant 2016;35:1385-98.

110.Ius F, Tudorache I, Warnecke G. Extracorporeal support, during and after lung transplantation: the history of an idea. J Thorac Dis 2018;10:5131-48.

111. Granton J, Mercier O, De Perrot M. Management of severe pulmonary arterial hypertension. Semin Respir Crit Care Med 2013;34:700-13.

112. Tudorache I, Sommer W, Kuhn C, et al. Lung transplantation for severe pulmonary hypertension-awake extracorporeal membrane oxygenation for postoperative left ventricular remodelling. Transplantation 2015;99:451-8.

113. Bîrsan T, Kranz A, Mares P, et al. Transient left ventricular failure following bilateral lung transplantation for pulmonary hypertension. J Heart Lung Transplant 1999;18:304-9.

114. Gupta S, Torres F, Bollineni S, et al. Left Ventricular Dysfunction After Lung Transplantation for Pulmonary Arterial Hypertension. Transplant Proc 2015;47:2732-6.

115. Rosenzweig EB, Chicotka S, Bacchetta M. Right ventricular assist device use in ventricular failure due to pulmonary arterial hypertension: Lessons learned. J Heart Lung Transplant 2016;35:1272-4.

116. Punnoose L, Burkhoff D, Rich S, et al. Right ventricular assist device in end-stage pulmonary arterial hypertension: insights from a computational model of the cardiovascular system. Prog Cardiovasc Dis 2012;55:234-43.e2.

117. Kylhammar D, Kjellstrom B, Hjalmarsson C, et al. A comprehensive risk stratification at early follow-up determines prognosis in pulmonary arterial hypertension. Eur Heart J 2018;39:4175-81.

118. Hoeper MM, Kramer T, Pan Z, et al. Mortality in pulmonary arterial hypertension: prediction by the 2015 European pulmonary hypertension guidelines risk stratification model. Eur Respir J 2017;50:1700740.

119. Benza RL, Gomberg-Maitland M, Miller DP, et al. The REVEAL Registry risk score calculator in patients newly diagnosed with pulmonary arterial hypertension. Chest 2012;141:354-62.

120. Moser B, Jaksch P, Taghavi S, et al. Lung transplantation 
for idiopathic pulmonary arterial hypertension on intraoperative and postoperatively prolonged extracorporeal membrane oxygenation provides optimally controlled reperfusion and excellent outcome. Eur J Cardiothorac Surg 2018;53:178-85.

121. Hoetzenecker K, Schwarz S, Muckenhuber M, et al. Intraoperative extracorporeal membrane oxygenation and the possibility of postoperative prolongation improve survival in bilateral lung transplantation. J Thorac Cardiovasc Surg 2018;155:2193-206.e3.

122.Egan TM, Murray S, Bustami RT, et al. Development of the new lung allocation system in the United States. Am J Transplant 2006;6:1212-27.

123. Gottlieb J. Lung allocation. J Thorac Dis 2017;9:2670-4. 124. Schaffer JM, Singh SK, Joyce DL, et al. Transplantation for idiopathic pulmonary arterial hypertension: improvement in the lung allocation score era. Circulation 2013;127:2503-13.

125.Egan TM, Edwards LB. Effect of the lung allocation score on lung transplantation in the United States. J Heart Lung Transplant 2016;35:433-9.

126. Chen H, Shiboski SC, Golden JA, et al. Impact of the lung allocation score on lung transplantation for pulmonary arterial hypertension. Am J Respir Crit Care Med 2009;180:468-74.

127. Chambers DC, Cherikh WS, Harhay MO, et al. The International Thoracic Organ Transplant Registry of the International Society for Heart and Lung Transplantation: Thirty-sixth adult lung and heart-lung transplantation Report-2019; Focus theme: Donor and recipient size match. J Heart Lung Transplant 2019;38:1042-55.

128. Yusen RD, Edwards LB, Kucheryavaya AY, et al. The Registry of the International Society for Heart and Lung Transplantation: Thirty-second Official Adult Lung and Heart-Lung Transplantation Report--2015; Focus Theme: Early Graft Failure. J Heart Lung Transplant 2015;34:1264-77.

Cite this article as: Inampudi C, Tedford RJ, Hemnes AR, Hansmann G, Bogaard HJ, Koestenberger M, Lang IM, Brittain EL. Treatment of right ventricular dysfunction and heart failure in pulmonary arterial hypertension. Cardiovasc Diagn Ther 2020;10(5):1659-1674. doi: 10.21037/cdt-20-348 